\title{
Metabolic memory: a vascular perspective
}

\author{
Thomas W Jax ${ }^{1,2}$
}

\begin{abstract}
Multiple and complex pathways promote the deleterious effects of hyperglycemia in diabetes, ultimately leading to micro- and macrovascular disease. Some of the known mechanisms in diabetic vascular disease may explain the initiation of the "metabolic memory", but fall short if long periods of time are involved.

Vascular research has been prolific in the past in finding links between microvascular dysfunction and subsequent macrovascular disease. Thus, this text will extend the current discussion of the "metabolic memory" by including available data from vascular research.

The hypothesis proposes that structural and functional changes in the microcirculation interact within the vascular continuum with larger arteries. This interaction may lead to subsequent upstream endothelial dysfunction, atherosclerosis and vascular complications ("Micro/ Macro Interaction"). The underlying microvascular structural changes may be more long-term and possibly mediate the "metabolic memory".

This hypothesis, that the "not-so new" interaction between micro-and macrovasculature may promote "metabolic memory" effects extends and unifies currently discussed theories.
\end{abstract}

\section{The vascular perspective of the metabolic memory}

In vascular research it is well established, that microvascular dysfunction eventually leads to subsequent macrovascular disease [1]. A dilation of prearterioles and arterioles results in an increase of shear stress, which triggers flow dependent dilation in conductance arteries [1,2], less shear stress secondary to microvascular dysfunction may lead to less vasodilation and thus endothelial dysfunction in conductance arteries.

In diabetes, hyperglycemia promotes both micro- and macrovascular damage by activating a network of multiple and complex pathways. Many of these may explain

\footnotetext{
Correspondence: thomas.jax@profil.com

${ }^{1}$ Profil Institut für Stoffwechselforschung, Hellersbergstrasse 9, 41460 Neuss, Germany
}

Full list of author information is available at the end of the article the initiation of the "metabolic memory" but fall short if long periods of time are involved. Structural changes in the microcirculation alter microvessels and their function, resulting in microvascular endpoints in the most susceptible organs.

The interaction within the vascular continuum between microvessels and larger arteries may lead to subsequent upstream endothelial dysfunction, atherosclerosis and vascular complications ("Micro/Macro Interaction"). In addition local intra vessel wall microvascular changes can promote localized atherosclerosis. These underlying microvascular structural changes may be more long-term and possibly mediate the "metabolic memory". The fact, that early intensive treatment of diabetes may be superior to intensification at a later disease stage indicates an early time window one has to make use of for intensive therapy in order to achieve a long-lasting therapeutic benefit by signifying the role of a structural fixation up to a "point of no return", when a regression of vascular disease progression is no longer possible. This extended, or rather unifying hypothesis will promote new research in this exiting area.

\section{Good metabolic control mediates long-term benefit}

One of the major principles of the clinical long-term management of patients with diabetes mellitus is to prevent cardiovascular (CV) complications. Recently it was observed in several large scale clinical trials, that an intensive antihyperglycaemic treatment of diabetic patients, both in type 1 and 2 , reduces the incidence of microvascular complications [3-5]. After the end of each study the participants were followed without any further intervention and, despite no further treatment differences, the advantage of intensive antidiabetic treatment persisted and even extended to a reduction of macrovascular events. The underlying cause of this phenomenon remains unclear; it is currently being discussed to be a "metabolic memory" effect: A defined period of good metabolic control conciliates a long term beneficial effect on cardiovascular endpoints. Several hypotheses, in particular the effects of a prolonged decreased 
oxidative challenge, are discussed. This comment extends the present view by introducing the role of macro- and microvascular interaction as a possible cause mediating "metabolic memory".

The global epidemic of diabetes leads to growing numbers of secondary cardiovascular complications. Cardiovascular mortality affects the majority of diabetic patients, the relative risk as compared to a non-diabetic population is several fold higher [6,7].

Tight metabolic control is the obvious approach to reduce the rate of cardiovascular events. Two very recent trials, ACCORD and ADVANCE, triggered a discussion, whether very tight metabolic control is really beneficial or not even contra productive $[8,9]$. Both trials explored in a large number of diabetic patients, whether an aggressive treatment algorithm to achieve good metabolic control can reduce micro- and/or macrovascular endpoints. The ADVANCE trial, although not finding a reduction of macrovascular endpoints, could show a reduction of diabetic nephropathy [8]. ACCORD was prematurely stopped because of higher mortality in the intensive treatment arm [9]. The underlying cause of these findings now is a matter of intense and controversial discussion. Both studies included diabetic patients with a history of cardiovascular disease, thus a more "advanced" subset of patients, in which the disease process might not be reversible.

Two other landmark studies showed differing results with regard to cardiovascular outcome [4,5]: although the initial results of the UKPDS study in newly diagnosed type 2 diabetic people [5] showed an improvement only in microvascular endpoints in the intensive treatment arm, the follow-up observation of another 10 years could also show a reduction of macrovascular endpoints and CV mortality in this group [4], despite of equal metabolic control (HbA1c) of both treatment arms after the end of the initial treatment period. The DCCT/EDIC trials showed very similar results for type 1 diabetic patients [3,10], including 1441 patients with a maximum of 5 years of type 1 diabetes and no complications.

The results of these studies led to a number of conclusions and new hypotheses, among which the concept of "metabolic memory" stands out. This hypothesis describes the observation that a prolonged tight metabolic control during early (newly diagnosed to 5 years) but not at later stage diabetes mellitus leads to sustained beneficial effects regarding micro- and macrovascular endpoints $[3-5,10,11]$. An earlier work by Garvey and co-workers [12] provided evidence for potential mechanisms. They demonstrated that an intensive insulin regimen in type 2 diabetic patients reversed the insulin resistance in muscle and liver as well as increased the beta cell insulin secretion without further use of insulin, claiming, that this would be caused by some "metabolic memory". In the present discussion the term "metabolic memory" implies that early glycaemic environment is "remembered" by target organs such as blood vessels, but also retina, heart, kidney, etc.[13]. The evolution of this concept has been recently discussed by Ceriello et al [13]. Briefly, the first reports of Kern reported two decades ago in a diabetic dog model, that poor glycaemic control followed by a period of good control did show the same rate of retinopathy as poorly controlled dogs [14]. Interestingly, Roy showed a shift of gene expression towards collagen IV and fibronectin expression in vitro (endothelial cells) and in diabetic rats (kidney cortex and myocardium) [15] with a similar design of a period with poor control followed by normalized glucose levels. These data implied that irreversible structural changes might be involved in the progression of late-term hyperglycaemic effects.

\section{The potential role of oxidative stress}

Hyperglycemia induces a large number of alterations at the cellular level of vascular tissue that potentially accelerate the atherosclerotic process. Three major processes are thought to interrelate and promote vascular changes, which include glycolysation of proteins, oxidative stress and protein kinase $C$ activation [16]. There exists a wealth of literature that highlights the role of oxidative stress in the development of vascular damage and subsequent atherosclerosis. Details are not within the scope of this paper and can be found elsewhere [17].

The potential relation between oxidative stress and the "metabolic memory" is presently the most discussed hypothesis [13]. This concept implies that a sustained exposure to reactive nitrogen and oxygen species (RNOS), mediates multiple downstream biological processes via covalent modification of proteins, nucleic acids and/or lipoproteins, which finally accounts for irreversible deterioration. On the other hand, a transient RNOS production on the short-term is an integral part of cellular signal transduction under physiological conditions [13].

Although this hypothesis is compelling, it would not explain an effect, that according to EDIC and UKPDS "metabolic memory" extends to beyond 10 years. To explain macrovascular disease these mechanisms would have to occur within the vessel walls of the macrovasculature, especially within the endothelium as the central cellular compartment of early atherosclerotic development. One could argue that early RNOS overload primes for the later development of macrovascular disease, since atherosclerosis is generally not reversible.

Several recent papers explore the possibility of epigenetic changes induced by hyperglycemia.. El-Osta and coworkers were able to show that transient hyperglycemia 
induced long-lasting activating epigenetic changes in aortic endothelial cells in vitro and in vivo in non-diabetic mice $[18,19]$. Various methylation or dymatylation events may lead to upregulation of NF $\kappa \mathrm{B}-\mathrm{p} 65$, which may lead to subsequent activation of pro-inflammatory pathways, possibly leading to micro- and macrovascular disease [20]. Tonna et al propose the involvement of epigenetic changes especially for the development of diabetic nephropathy [20]. Although this approach is very compelling, more in vivo data will be needed. As vascular endothelium is an organ with a high turnover and regenerative capacity $[21,22]$, the question remains unanswered how early endothelial changes mediated through oxidative stress and/or epigenetic changes can account for long-term macrovascular risk. Additionally, multiple mechanisms including induction of an antioxidative response and counter regulation of gene expression exist to maintain endothelial integrity [23-26].

Reality is probably more complex and thus the current hypothesis of the "metabolic memory" may be extended by (re-)introducing a vascular perspective. A central observation of EDIC and UKPDS is, that diabetic people who were recruited early in their disease career (newly diagnosed to 5 years), despite of treatment modalities, first presented with microvascular disease only whereas macrovascular disease occurred much later. Patients with intensive treatment developed less micro- and later also less macrovascular disease. These simplified observations may lead to the conclusion that there is a timely order, and that microvascular disease may be a prerequisite for macrovascular complications in these patients.

\section{Micro- and Macrovasculature}

The above findings are supported by observations that microcirculatory changes correlate with macrovascular atherosclerosis and the occurrence of cardiovascular events. Wong and co-workers found in the "Atherosclerosis Risk in Communities"-study (ARIC), that retinal arteriolar narrowing as an established marker of microvascular damage is closely associated with the risk of events related to coronary heart disease [27]. Although these effects were predominantly seen in women, they were independent of hypertension and diabetes mellitus. Other studies conformed this association between retinal changes and risk for coronary artery disease in general [28], micro-and macrovascular changes in diabetes $[28,29]$, subclinical atherosclerotic disease [28] and the risk of stroke [28,30-32].

It is important to realize, that microvascular dysfunction is not limited to one organ but rather a systemic process [33,34]. In hypertension for example histopathological changes in retinal and coronary arteries are very similar $[35,34,33]$. There also exists a microangiopathic process within the vessel wall of conduit arteries resembling that of retinal changes [36], which are discussed to precede macrovascular changes. Thus microvascular changes in a particular vascular bed (e.g. retinal arterioles) may allow comparisons to other vascular regions.

\section{Fibrosis of the microvascular interstitium}

Besides of functional changes of the microcirculation structural changes are mediating long term complications. As mentioned above, it is well established that hyperglycaemia mediates vascular changes through several pathways [37]. These pathways are interconnected with each other and include the increased synthesis of sorbitol and hexosamines, glycosylation of proteins, synthesis of "advanced glycosylation end products" (AGE), and oxidative stress (figure 1). The downstream effects in the microvasculature are mainly characterized by changes of the extracellular matrix composition and structure. Induction of inflammatory processes through receptor binding of AGEs or oxidative stress mediate changes of the structure of the extracellular matrix [37]. Subsequent fibrosis and the extension of extracellular structures impair capillary blood flow and in particular reduces capillary density (figure 1) [38-40]. Reduced blood flow may then facilitate microvascular complications. These become apparent the earliest in the most vulnerable organs, which are, among others, retina and kidney. Early diabetic microvascular changes relate to a thickening of the basement membrane in the capillaries. These changes occur throughout the whole body and include arterioles in the glomeruli, retina, skin, muscle, and myocardium, resulting in classic diabetic microangiopathy [41]. Various mechanisms have been proposed for diabetic microvascular complications [41], but the endothelium plays a major role in the disease processes. Surprisingly, endothelial cells show a high heterogeneity in structure and function throughout the vascular tree [42-44]. This relates to a variety of functional differences between different vascular beds, such as permeability, hemostasis, vasomotor tone, leukocyte transmigration and others. These may, at least in part, explain the susceptibility of certain organs to diabetic microvascular damage.

\section{The vascular continuum: Interaction between micro- and macrovasculature}

Conductance arteries provide sufficient blood flow to end organs, but blood demand is not regulated through dilatation of the larger arteries but rather through the alteration of microvascular resistance [45]. This function is located within the specific organ at the level of the resistance arteries or arterioles (figure 2). The microcirculation regulates vasomotion and permeability and can thus adapt blood flow according to local metabolic needs $[46,47]$. 


\section{Hyperglycemia

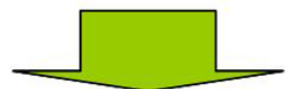 \\ Metabolic Factors $\uparrow$}

Sorbitol-

Hexosamine-
Pathway $\uparrow$

AGE $\uparrow$

Oxidative

FFA $\uparrow$

Pathway $\uparrow$

Stress $\uparrow$

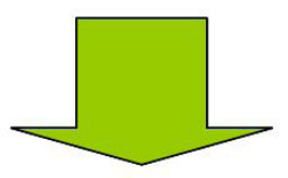

Inflammation $\uparrow$

Collagen-

Extracellular

Synthesis $\uparrow$

Matrix $\uparrow$

Density of

Capillaries $\downarrow$

5 years
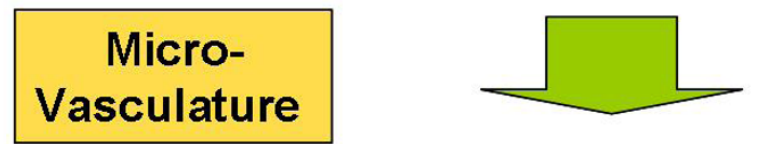

Microvascular Endpoints

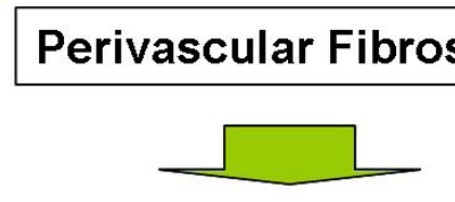

Blood-Flow

Regulation $\downarrow$

Micro/ Macro Interaction
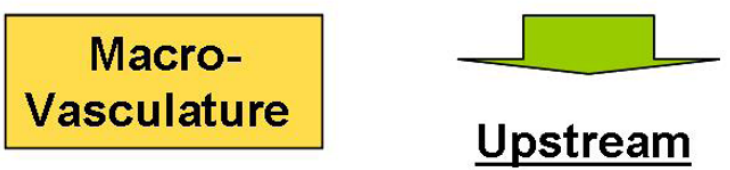

Macrovascular Function $\downarrow$

Endothelial Dysfunction

20 years

\begin{tabular}{|c|}
\hline Atherosclerosis \\
Macrovascular Endpoints
\end{tabular}

Time

Figure 1 Hyperglycemia and vascular outcome. Hyperglycemia activates multiple and complex pathogenetically relevant pathways. Inflammatory processes lead to a thickening of the basal membrane of microvessels and perivascular fibrosis resulting in microvascular

endpoints in the most susceptible organs, such as renal insufficiency and retinopathy. The structural changes also result in functional impairment and a reduction in blood flow regulation, which in turn reduces macrovascular endothelial function ("Micro/Macro Interaction"). The loss of endothelial protection may lead to the subsequent development of atherosclerosis. The structural changes within the microcirculation may account for building up a "metabolic memory". 




For example, coronary vascular resistance, which is well studied, under physiological conditions is mainly regulated through microvessels; conductance vessels only participate with about $5 \%$ to total coronary resistance $[45,48-50]$. A common misperception may be that there is only little or no interaction between macro- and microcirculation and vice versa, but rather the opposite is the case. Macrovasculature can influence downstream resistance arteries through several pathways: A hemodynamically relevant stenosis $>50 \%$ of lumen reduction can be compensated through lowering downstream vascular resistance metabolically (e.g. for maintenance of oxygen supply) [51,52]. This reduces the amplitude of the flow reserve, so that if needed, flow reserve may not be sufficient for adequate supply of the end organ, which may in turn lead to symptoms such as angina pectoris in the heart $[53,54]$. Also, repeated microembolisms may alter downstream vascular resistance (reviewed in [45]).

On the other hand microvasculature may also influence the function of upstream larger arteries. Patients with hypertensive heart disease present with a substantially reduced coronary flow reserve [55]. Coronary microangiopathy is associated with a reduction of upstream dilatatory function of epicardial coronary arteries [56]. This association is correlated to the degree of myocardial hypertrophy. The interface may, again, be endothelial function. Vasodilatory capacity of large 
arteries is mainly dependent on acute stimulation of nitric oxide synthesis of endothelial cells. Shear stress is one of the major regulators of local NO-synthesis. In principle, an increase of a normal microcirculatory flowreserve will increase upstream flow mediated vasodilation by a factor 3-6 [45,57]. Microvascular dysfunction with a reduced flow reserve will lead to a reduced shear stress-induced NO synthesis in upstream macrovessels [58]. This implies that structural changes such as perivascular fibrosis of microvessels can directly influence upstream arteries and cause endothelial dysfunction (over time) and subsequent atherosclerosis (figures 1 and 2). This proposed mechanism may represent the cause of the "metabolic memory". Since the effect was only seen in diabetic patients who were included in studies shortly after their diagnosis, microvascular structural changes might represent a "point of no return", after which an intensive treatment might less effective or not effective at all. (figure 1).

Indirect studies suggest that a long-term reduction of microcirculatory function would lead to endothelial dysfunction and consequent atherosclerosis. Kelm and coworkers studied 62 hypertensive patients with myocardial microangiopathy and without any macrovascular coronary artery disease (CAD) for 10 years [45]. 28 patients developed relevant coronary artery disease, which would be the equivalent of an incidence for CAD of $8 \%$. This is multiple times higher than the yearly incidence of CAD in American (0.37\%) or Australian (0.11\%) populations [45]. The risk of major cardiac events was $2-3$ fold higher.

In a recent review Oresanu and Plutzky hypothesize, that microangiopathy in the neovasculature of vaso vasorum may propagate and accelerate diabetic atherosclerosis [41]. The vaso vasorum is a network of microvessels in the adventitia and media of large arteries [59] providing the vascular wall of these large arteries with nutrients but also influence lipid deposition and metabolism and neurohumoral factors [59]. Hypoxia and macrophages within atherosclerotic plaques may promote intraplaque and intra vessel wall angiogenesis and alter vessel wall microcirculation [36]. This hypothesis would supplement the theory of this paper, in particular the occurrence of plaques at certain, rather specific locations such as bifurcations.

In addition, several authors suggested, that microvascular structure I not only the site of vascular resistance but probably also the origin of most of the wave reflections generating increased central blood pressure and thus influencing large artery stiffness [60]. Small artery remodelling can be observed in hypertensive diabetics as well as in patients with diabetes mellitus alone, underlining the role of diabetes for the pathophysiology of microvascular disease [61-63]. Drugs that somehow improve microvascular structure are also effective for improving the mechanical properties of large arteries [62]

\section{Conclusion}

Although diabetes specific data is not yet available, there exist strong analogies to hypertensive vascular disease, which will allow well designed experiments and trials to test this hypothesis. It could be possible that microvascular events in the earlier course of the disease process may be reversible through adaption processes whereas macrovascular changes may be more irreversible through maladaptation.

Proof-of-concept studies as well as clinical studies will be needed to support this unifying concept, but a better understanding of the interplay of metabolism, microand macrovasculature may ultimately promote new therapeutic options and better patient outcome.

\section{Acknowledgements}

I thank Drs. Ulrike Hövelmann, Sabine Arnold, Freimut Schlies, and Tim Heise, for the prolific discussion and thorough review of this paper.

\section{Author details}

${ }^{1}$ Profil Institut für Stoffwechselforschung, Hellersbergstrasse 9, 41460 Neuss, Germany. ${ }^{2}$ Herzzentrum Wuppertal, Medizinische Klinik 3, Helios Klinikum, Universität Witten/Herdecke, Germany.

\section{Competing interests}

The author declares that they have no competing interests.

Received: 1 July 2010 Accepted: 14 September 2010

Published: 14 September 2010

\section{References}

1. Camici PG, Crea F: Coronary microvascular dysfunction. N Engl J Med 2007, 356:830-840.

2. Chilian WM: Coronary microcirculation in health and disease. Summary of an NHLBI workshop. Circulation 1997, 95:522-528.

3. Nathan DM, Cleary PA, Backlund JY, Genuth SM, Lachin JM, Orchard TJ, Raskin P, Zinman B: Intensive diabetes treatment and cardiovascular disease in patients with type 1 diabetes. N Engl J Med 2005, 353:2643-2653.

4. Holman RR, Paul SK, Bethel MA, Matthews DR, Neil HA: 10-year follow-up of intensive glucose control in type 2 diabetes. N Engl J Med 2008, 359:1577-1589.

5. Intensive blood-glucose control with sulphonylureas or insulin compared with conventional treatment and risk of complications in patients with type 2 diabetes (UKPDS 33). UK Prospective Diabetes Study (UKPDS) Group. Lancet 1998, 352:837-853.

6. Feskens EJ, Kromhout D: Glucose tolerance and the risk of cardiovascular disease: the Zutphen Study. J Clin Epidemiol 1992, 45:1327-1334.

7. Skyler JS, Bergenstal R, Bonow RO, Buse J, Deedwania P, Gale EA, Howard BV, Kirkman MS, Kosiborod M, Reaven P, Sherwin RS: Intensive glycemic control and the prevention of cardiovascular events: implications of the ACCORD, ADVANCE, and VA diabetes trials: a position statement of the American Diabetes Association and a scientific statement of the American College of Cardiology Foundation and the American Heart Association. Circulation 2009, 119:351-357.

8. Patel A, MacMahon S, Chalmers J, Neal B, Billot L, Woodward M, Marre M, Cooper M, Glasziou P, Grobbee D, Hamet P, Harrap S, Heller S, Liu L, Mancia G, Mogensen CE, Pan C, Poulter N, Rodgers A, Williams B, Bompoint S, de Galan BE, Joshi R, Travert F: Intensive blood glucose 
control and vascular outcomes in patients with type 2 diabetes. $N$ Engl J Med 2008, 358:2560-2572.

9. Gerstein HC, Miller ME, Byington RP, Goff DC Jr, Bigger JT, Buse JB, Cushman WC, Genuth S, Ismail-Beigi F, Grimm RH Jr, Probstfield JL, SimonsMorton DG, Friedewald WT: Effects of intensive glucose lowering in type 2 diabetes. N Engl J Med 2008, 358:2545-2559.

10. The effect of intensive treatment of diabetes on the development and progression of long-term complications in insulin-dependent diabetes mellitus. The Diabetes Control and Complications Trial Research Group. N Engl J Med 1993, 329:977-986.

11. White NH, Sun W, Cleary PA, Danis RP, Davis MD, Hainsworth DP, Hubbard LD, Lachin JM, Nathan DM: Prolonged effect of intensive therapy on the risk of retinopathy complications in patients with type 1 diabetes mellitus: 10 years after the Diabetes Control and Complications Trial. Arch Ophthalmol 2008, 126:1707-1715.

12. Garvey WT, Olefsky JM, Griffin J, Hamman RF, Kolterman OG: The effect of insulin treatment on insulin secretion and insulin action in type II diabetes mellitus. Diabetes 1985, 34:222-234.

13. Ceriello A, Ihnat MA, Thorpe JE: Clinical review 2: The "metabolic memory": is more than just tight glucose control necessary to prevent diabetic complications? J Clin Endocrinol Metab 2009, 94:410-415.

14. Engerman RL, Kern TS: Progression of incipient diabetic retinopathy during good glycemic control. Diabetes 1987, 36:808-812.

15. Roy S, Sala R, Cagliero E, Lorenzi M: Overexpression of fibronectin induced by diabetes or high glucose: phenomenon with a memory. Proc Natl Acad Sci USA 1990, 87:404-408.

16. Aronson D, Rayfield EJ: How hyperglycemia promotes atherosclerosis: molecular mechanisms. Cardiovasc Diabetol 2002, 1:1.

17. Szabo C: Role of nitrosative stress in the pathogenesis of diabetic vascular dysfunction. Br J Pharmacol 2009, 156:713-727.

18. Brasacchio D, Okabe J, Tikellis C, Balcerczyk A, George P, Baker EK, Calkin AC, Brownlee M, Cooper ME, El Osta A: Hyperglycemia induces a dynamic cooperativity of histone methylase and demethylase enzymes associated with gene-activating epigenetic marks that coexist on the lysine tail. Diabetes 2009, 58:1229-1236.

19. El Osta A, Brasacchio D, Yao D, Pocai A, Jones PL, Roeder RG, Cooper ME, Brownlee M: Transient high glucose causes persistent epigenetic changes and altered gene expression during subsequent normoglycemia. J Exp Med 2008, 205:2409-2417.

20. Tonna S, El-Osta A, Cooper ME, Tikellis C: Metabolic memory and diabetic nephropathy: potential role for epigenetic mechanisms. Nat Rev Nephrol 2010, 6:332-341.

21. Caplan BA, Schwartz CJ: Increased endothelial cell turnover in areas of in vivo Evans Blue uptake in the pig aorta. Atherosclerosis 1973, 17:401-417.

22. Crosby JR, Kaminski WE, Schatteman G, Martin PJ, Raines EW, Seifert RA, Bowen-Pope DF: Endothelial cells of hematopoietic origin make a significant contribution to adult blood vessel formation. Circ Res 2000, 87:728-730

23. Schatteman GC, Hanlon HD, Jiao C, Dodds SG, Christy BA: Blood-derived angioblasts accelerate blood-flow restoration in diabetic mice. J Clin Invest 2000, 106:571-578.

24. Zampetaki A, Kirton JP, Xu Q: Vascular repair by endothelial progenitor cells. Cardiovasc Res 2008, 78:413-421.

25. Dimmeler S, Zeiher AM: Vascular repair by circulating endothelial progenitor cells: the missing link in atherosclerosis? J Mol Med 2004, 82:671-677.

26. Urbich C, Dimmeler S: Endothelial progenitor cells: characterization and role in vascular biology. Circ Res 2004, 95:343-353.

27. Wong TY, Klein R, Sharrett AR, Duncan BB, Couper DJ, Tielsch JM, Klein BE, Hubbard LD: Retinal arteriolar narrowing and risk of coronary heart disease in men and women. The Atherosclerosis Risk in Communities Study. JAMA 2002, 287:1153-1159.

28. McGeechan K, Liew G, Macaskill P, Irwig L, Klein R, Klein BE, Wang JJ, Mitchell P, Vingerling JR, Dejong PT, Witteman JC, Breteler MM, Shaw J, Zimmet $\mathrm{P}$, Wong TY: Meta-analysis: retinal vessel caliber and risk for coronary heart disease. Ann Intern Med 2009, 151:404-413.

29. Cheung N, Wang JJ, Klein R, Couper DJ, Sharrett AR, Wong TY: Diabetic retinopathy and the risk of coronary heart disease: the Atherosclerosis Risk in Communities Study. Diabetes Care 2007, 30:1742-1746.

30. McGeechan K, Liew G, Macaskill P, Irwig L, Klein R, Klein BE, Wang JJ, Mitchell P, Vingerling JR, de Jong PT, Witteman JC, Breteler MM, Shaw J,
Zimmet $P$, Wong TY: Prediction of incident stroke events based on retinal vessel caliber: a systematic review and individual-participant meta-analysis. Am J Epidemiol 2009, 170:1323-1332.

31. Witt N, Wong TY, Hughes AD, Chaturvedi N, Klein BE, Evans R, McNamara M, Thom SA, Klein R: Abnormalities of retinal microvascular structure and risk of mortality from ischemic heart disease and stroke. Hypertension 2006, 47:975-981.

32. Mitchell P, Wang JJ, Wong TY, Smith W, Klein R, Leeder SR: Retinal microvascular signs and risk of stroke and stroke mortality. Neurology 2005, 65:1005-1009.

33. Lekakis JP, Papamichael CM, Vemmos CN, Voutsas AA, Stamatelopoulos SF, Moulopoulos SD: Peripheral vascular endothelial dysfunction in patients with angina pectoris and normal coronary arteriograms. J Am Coll Cardiol 1998, 31:541-546.

34. Sax FL, Cannon RO, Hanson C, Epstein SE: Impaired forearm vasodilator reserve in patients with microvascular angina. Evidence of a generalized disorder of vascular function? N Engl J Med 1987, 317:1366-1370.

35. Tso MO, Jampol LM: Pathophysiology of hypertensive retinopathy. Ophthalmology 1982, 89:1132-1145.

36. Sluimer JC, Gasc JM, van Wanroij JL, Kisters N, Groeneweg M, Sollewijn Gelpke MD, Cleutjens JP, van den Akker LH, Corvol P, Wouters BG, Daemen MJ, Bijnens AP: Hypoxia, hypoxia-inducible transcription factor, and macrophages in human atherosclerotic plaques are correlated with intraplaque angiogenesis. J Am Coll Cardiol 2008, 51:1258-1265.

37. Brownlee M: Biochemistry and molecular cell biology of diabetic complications. Nature 2001, 414:813-820.

38. Gross ML, Heiss N, Weckbach M, Hansen A, El Shakmak A, Szabo A, Munter K, Ritz E, Amann K: ACE-inhibition is superior to endothelin A receptor blockade in preventing abnormal capillary supply and fibrosis of the heart in experimental diabetes. Diabetologia 2004, 47:316-324.

39. Mauer SM, Steffes MW, Ellis EN, Sutherland DE, Brown DM, Goetz FC: Structural-functional relationships in diabetic nephropathy. J Clin Invest 1984, 74:1143-1155.

40. Mizushige K, Yao L, Noma T, Kiyomoto H, Yu Y, Hosomi N, Ohmori K, Matsuo H: Alteration in left ventricular diastolic filling and accumulation of myocardial collagen at insulin-resistant prediabetic stage of a type II diabetic rat model. Circulation 2000, 101:899-907.

41. Orasanu G, Plutzky J: The pathologic continuum of diabetic vascular disease. J Am Coll Cardiol 2009, 53:S35-\$42.

42. Aird WC: Phenotypic heterogeneity of the endothelium: II. Representative vascular beds. Circ Res 2007, 100:174-190.

43. Aird WC: Phenotypic heterogeneity of the endothelium: I. Structure, function, and mechanisms. Circ Res 2007, 100:158-173.

44. Chi JT, Chang HY, Haraldsen G, Jahnsen FL, Troyanskaya OG, Chang DS, Wang Z, Rockson SG, van de RM, Botstein D, Brown PO: Endothelial cell diversity revealed by global expression profiling. Proc Natl Acad Sci USA 2003, 100:10623-10628.

45. Kelm M: [Interaction of the coronary macro- and microcirculation]. $Z$ Kardiol 2001, 90:946-952.

46. Wiernsperger NF: In defense of microvascular constriction in diabetes. Clin Hemorheol Microcirc 2001, 25:55-62.

47. Sheetz MJ, King GL: Molecular understanding of hyperglycemia's adverse effects for diabetic complications. JAMA 2002, 288:2579-2588.

48. Feigl EO: Coronary physiology. Physiol Rev 1983, 63:1-205.

49. Marcus ML, Chilian WM, Kanatsuka H, Dellsperger KC, Eastham CL, Lamping KG: Understanding the coronary circulation through studies at the microvascular level. Circulation 1990, 82:1-7.

50. Tiefenbacher $C P$, Chilian WM: Heterogeneity of coronary vasomotion. Basic Res Cardiol 1998, 93:446-454.

51. Deussen A, Schrader J: Cardiac adenosine production is linked to myocardial pO2. J Mol Cell Cardiol 1991, 23:495-504.

52. Heusch G, Baumgart D, Camici P, Chilian W, Gregorini L, Hess O, Indolfi C, Rimoldi O: alpha-adrenergic coronary vasoconstriction and myocardial ischemia in humans. Circulation 2000, 101:689-694.

53. Gould KL: Pressure-flow characteristics of coronary stenoses in unsedated dogs at rest and during coronary vasodilation. Circ Res 1978, 43:242-253.

54. Hess OM, Buchi M, Kirkeeide R, Niederer P, Anliker M, Gould KL, Krayenbuhl HP: Potential role of coronary vasoconstriction in ischaemic heart disease: effect of exercise. Eur Heart J 1990, 11(Suppl B):58-64. 
55. Strauer BE: The significance of coronary reserve in clinical heart disease. $J$ Am Coll Cardiol 1990, 15:775-783.

56. Zeiher AM, Drexler $H$, Wollschlager $H$, Just $H$ : Endothelial dysfunction of the coronary microvasculature is associated with coronary blood flow regulation in patients with early atherosclerosis. Circulation 1991, 84:1984-1992.

57. Antony I, Lerebours $G$, Nitenberg A: Loss of flow-dependent coronary artery dilatation in patients with hypertension. Circulation 1995, 91:1624-1628.

58. Sessa WC, Pritchard K, Seyedi N, Wang J, Hintze TH: Chronic exercise in dogs increases coronary vascular nitric oxide production and endothelial cell nitric oxide synthase gene expression. Circ Res 1994, 74:349-353.

59. Hayden MR, Tyagi SC: Vasa vasorum in plaque angiogenesis, metabolic syndrome, type 2 diabetes mellitus, and atheroscleropathy: a malignant transformation. Cardiovasc Diabetol 2004, 3:1.

60. Rizzoni D, Muiesan ML, Porteri E, De CC, Boari GE, Salvetti M, Paini A, Rosei EA: Vascular remodeling, macro- and microvessels: therapeutic implications. Blood Press 2009, 18:242-246.

61. Rizzoni D, Porteri E, Guelfi D, Muiesan ML, Valentini U, Cimino A, Girelli A, Rodella L, Bianchi R, Sleiman I, Rosei EA: Structural alterations in subcutaneous small arteries of normotensive and hypertensive patients with non-insulin-dependent diabetes mellitus. Circulation 2001, 103:1238-1244.

62. Rizzoni D, Rosei EA: Small artery remodeling in diabetes mellitus. Nutr Metab Cardiovasc Dis 2009, 19:587-592.

63. Schofield I, Malik R, Izzard A, Austin C, Heagerty A: Vascular structural and functional changes in type 2 diabetes mellitus: evidence for the roles of abnormal myogenic responsiveness and dyslipidemia. Circulation 2002, 106:3037-3043.

doi:10.1186/1475-2840-9-51

Cite this article as: Jax: Metabolic memory: a vascular perspective.

Cardiovascular Diabetology 2010 9:51.

\section{Submit your next manuscript to BioMed Central and take full advantage of:}

- Convenient online submission

- Thorough peer review

- No space constraints or color figure charges

- Immediate publication on acceptance

- Inclusion in PubMed, CAS, Scopus and Google Scholar

- Research which is freely available for redistribution

Submit your manuscript at www.biomedcentral.com/submit 